\title{
Effects of meteorological factors on the composition of selected fungal spores in the air
}

\author{
Agnieszka Grinn-Gofroń • Beata Bosiacka
}

Received: 20 December 2013/Accepted: 30 August 2014/Published online: 12 September 2014

(C) The Author(s) 2014. This article is published with open access at Springerlink.com

\begin{abstract}
The aim of the study was to determine functional relationships between composition of air spora and meteorological factors, using multivariate statistical technique: canonical correspondence analysis (CCA). Analyses were conducted for the data collected during the 4 year (2007-2010) and, in order to show the dynamics of such relationships, for each year separately. The CCA results indicated that all statistically significant variables accounted for $15.3 \%$ of the total variance in the spore data in the 4 years. The largest amount of the total variance was explained in this period by the mean air temperature $(9.2 \%)$. The meteorological factors impacted spore composition differently in different years, when analysis was done for each year separately. The highest values of the total variance in the spore data, explained by the statistically significant variables, were found in 2010 $(32.3 \%)$, with the highest contribution of mean air temperature $(23.8 \%)$. In that year, the above-mentioned parameter had the lowest value in comparison to other years. Canonical correspondence analysis provides not only a comprehensive assessment of the impact of meteorological factors on specific spore combinations in the air, but also informative graphical presentations of the results, illustrating the correlation
\end{abstract}

A. Grinn-Gofroń $(\bowtie) \cdot$ B. Bosiacka

Department of Plant Taxonomy and Phytogeography, Faculty of Biology, University of Szczecin, Waska 13 Street, 71-415 Szczecin, Poland

e-mail: agofr@univ.szczecin.pl between the occurrence of particular spore taxa and meteorological variables.

Keywords Fungal spore composition . Meteorological parameters $\cdot$ CCA

\section{Introduction}

Fungal spores are an ever-present component of the air with concentrations and compositions known to fluctuate according to the complex interaction between biological and environmental factors such as: geographical location, air pollution, weather conditions, human activity and local source of vegetation. Effects of meteorological factors on the spore occurrence in the air have been highlighted by many authors for many geographical domains (Hasnain 1993; Hjelmroos 1993; Katial et al. 1997; Li and Kendrick 1995a; Oliveira et al. 2009a; Troutt and Levetin 2001). Aerobiological studies enable us to ascertain the concentration of the fungal spores present in the atmosphere and give better understanding of the relationship between their concentrations and the weather parameters. Most of these studies were based on simple descriptive statistics, such as Pearson or Spearman's correlation coefficients, or on multiple technique, such as the Duncan multiple range test and multiple regression model (Katial et al. 1997; AnguloRomero et al. 1999; Mitakakis et al. 2001; Troutt and 
Levetin 2001; Stennett and Beggs 2004). For the three types of spores (Alternaria, Cladosporium and Ganoderma), the predictive models were developed using advanced statistical methods like: artificial neural networks (ANN) and multivariate regression trees (MRT) (Grinn-Gofroń and Strzelczak 2008a, 2008b, 2009, 2011). All these studies put emphasis on the statistical analysis of the correlation between the level of concentration of particular fungal spore types and weather parameters, however do not examine the complex composition of spores and its dependence on meteorological factors. These phenomena have been analyzed in only a few studies (Hjelmroos 1993; Li and Kendrick 1995a, 1995b).

The aim of this study was to determine the dependence between selected meteorological factors and the composition of spores in the air during the 4-year period. In order to show the dynamics of these relationships, the same analyses were performed for each year separately.

\section{Materials and methods}

The data of this study were collected in Szczecin, which is located in the north-western part of Poland, at latitude and longitude of approximately $53^{\circ} 25^{\prime} \mathrm{N}$, and $14^{\circ} 35^{\prime} \mathrm{E}$, respectively. The climate in Szczecin is temperate with a clear influence of the Baltic Sea. The driest months are February and March; the rainiest and hottest-July; and the coolest-January. The annual mean temperature is around $8{ }^{\circ} \mathrm{C}$, and the difference between warmer and colder monthly averages is significant. Annual air humidity is between 70 and $75 \%$, and the total annual precipitation varies between 500 and $550 \mathrm{~mm}$ (Woś 1999).

Samples were collected using the methods described by the British Aerobiology Federation (1995). The investigation was based on aerobiological monitoring performed in 2007-2010. Airborne fungal spores were continuously monitored, using a sevenday Hirst-type volumetric spore trap manufactured by Lanzoni, Italy, with a flow rate of $10 \mathrm{~L} \mathrm{~min}^{-1}$. The sampler was placed on the roof of University of Szczecin at the height of $21 \mathrm{~m}$ above the ground level approximately $5 \mathrm{~km}$ from the city center. Sampler drums were changed weekly, and the tapes were cut into 48-mm segments representing the previous 7 days. Spores were trapped onto a Melinex adhesive tape, and cut into daily parts. Each segment of tape was placed on a microscope glass, colored using lacto phenol Cotton Blue mountant and closed with cover slips, and sealed with nail varnish the next day as described in details by the British Aerobiology Federation (1995). The daily mean concentration of the number of fungal spores was determined using an optical microscope at a magnification of $400 \times$ along one lengthwise traverse. Thus, the final counts of fungal spores were expressed as average daily number of spores per cubic meter of air. In order to verify the accuracy of calculations performed under the microscope, most of the samples have been reviewed using a microscopic camera connected to a computer screen.

The spore data were analyzed in order to determine the beginning, the end and the duration of a spore season, using the $90 \%$ method. The beginning of a season was defined as the date when $5 \%$ of the seasonal cumulative spore count was trapped and the end of a season as the date when $95 \%$ of the seasonal cumulative spore count was reached.

The meteorological data covering 4 years of studies were provided by the Automatic Weather Station (Vaisala MAWS101). The meteorological station was located in the immediate neighborhood of the Lanzoni trap.

\subsection{Data analysis}

Effects of selected weather parameters on airborne fungal spore composition were assessed using the software package CANOCO v. 4.5 (ter Braak and Šmilauer 2002). Fungal spore distribution patterns in relation to meteorological variables were determined by canonical correspondence analysis (CCA), after detrended correspondence analysis (DCA) results detected an unimodal structure of the spore data. A complete CCA was performed including eight selected meteorological variables: dew point temperature (DP), precipitation (PRECIP), relative humidity (RH), minimum air temperature (TMIN), maximum air temperature (TMAX), mean air temperature (TME), maximum wind speed (WINDMAX) and mean wind speed (WINDME). The spore and meteorological data were log transformed (by a modified formula available in CANOCO): $\mathrm{Y}_{k i}^{*}=\log \left(\mathrm{A} y_{k i}+\right.$ $\mathrm{B})$, where $y_{k i}$ is the concentration of $k$ spores in $i$ sample; the coefficients A and B are standard set as 1 .

Tests of significance of the first and all canonical axes were evaluated for the statistical assessment of 
Table 1 Summary of CCA for samples collected in Szczecin (NW Poland)

\begin{tabular}{|c|c|c|c|c|c|c|}
\hline & Axes & 2007 & 2008 & 2009 & 2010 & $2007-2010$ \\
\hline \multirow[t]{4}{*}{ Eigenvalues } & I & 0.122 & 0.088 & 0.088 & 0.175 & 0.065 \\
\hline & II & 0.015 & 0.045 & 0.014 & 0.010 & 0.018 \\
\hline & III & 0.011 & 0.005 & 0.005 & 0.003 & 0.003 \\
\hline & IV & 0.004 & 0.004 & 0.003 & 0.002 & 0.001 \\
\hline \multirow[t]{4}{*}{ Fungal spores-environment correlations } & I & 0.627 & 0.632 & 0.655 & 0.785 & 0.603 \\
\hline & II & 0.381 & 0.437 & 0.334 & 0.355 & 0.310 \\
\hline & III & 0.338 & 0.361 & 0.290 & 0.196 & 0.181 \\
\hline & IV & 0.330 & 0.331 & 0.189 & 0.243 & 0.120 \\
\hline \multirow[t]{4}{*}{ Cumulative percentage variance of fungal spore data } & $\mathrm{I}$ & 19.1 & 13.7 & 14.9 & 29.8 & 10.0 \\
\hline & II & 21.4 & 20.6 & 17.2 & 31.5 & 12.8 \\
\hline & III & 23.1 & 21.4 & 18.2 & 32.0 & 13.2 \\
\hline & IV & 23.8 & 22.1 & 18.6 & 32.3 & 13.4 \\
\hline \multirow{4}{*}{$\begin{array}{l}\text { Cumulative percentage variance of fungal } \\
\text { spores-environment relationship }\end{array}$} & $\mathrm{I}$ & 79.1 & 61.1 & 78.6 & 91.2 & 74.3 \\
\hline & II & 88.5 & 92.0 & 91.1 & 96.4 & 95.2 \\
\hline & III & 95.6 & 95.5 & 95.9 & 97.9 & 98.1 \\
\hline & IV & 98.4 & 98.4 & 98.2 & 99.1 & 99.3 \\
\hline Sum of all eigenvalues/total inertia & & 0.639 & 0.642 & 0.591 & 0.589 & 0.654 \\
\hline Sum of all canonical eigenvalues & & 0.154 & 0.144 & 0.112 & 0.192 & 0.108 \\
\hline Percentage of explained fungal spore data variance & & 24.1 & 24.4 & 20.3 & 32.6 & 16.5 \\
\hline
\end{tabular}

the relation between airborne fungal spores and environmental variables (Monte Carlo test: 499 permutations under reduced model). The Monte Carlo permutation test was further applied in order to determine the statistical significance of meteorological variables in explaining the fungal spore variation in the air. For this purpose, "stepwise forward selection" of explanatory variables was used (available in CANOCO). The procedure started with selection of the best explanatory variable (a variable that best explains the total data variance), and the sequence (rank) of other variables was determined according to their decreasing importance in explaining the total variance in the data set, together with the previously selected variables. Therefore, a value of "extra fit" was calculated (Lambda A), which is a change in the sum of all CCA eigenvalues when another variable is added. Additionally, statistical significance of each variable was calculated $(p)$. Variation in the airborne fungal spore composition, explained by meteorological variables included in the analysis, was expressed in a percentage - the ratio of the sum of all canonical eigenvalues to the value of total variance (total inertia). Variation in the spore composition explained by individual variables was calculated from the ratio of Lambda A to the total variance (total inertia), expressed in a percentage.

\section{Results}

The DCA results revealed that the gradient length represented by the first ordination axis was greater than 3 SD in all cases (in 2007: 3.168, in 2008: 3.349, in 2009: 4.014, in 2007-2010: 3.708); therefore, the direct CCA ordinations was performed.

The CCA results obtained indicated that all the applied variables accounted for $16.5 \%$ of the total variance in the spore data in 4 years (2007-2010) (Table 1). First axis and all canonical axes were significant as tested by the unrestricted Monte Carlo permutation test ( $p=0.002$ ) (Table 2).

The results of stepwise forward selection of variables revealed that in the above-mentioned period, four out of eight included meteorological variables (DP, RH, TME and WINDME) were statistically significant $(p \leq 0.05)$, and accounted for $15.3 \%$ of the total variance in the airborne fungal spore occurrence. The largest amount of the total variance was explained by the TME (9.2\%) (Table 3). 
Table 2 Results of the tests of significance of the first and all canonical axes

\begin{tabular}{llccccc}
\hline & Axes & 2007 & 2008 & 2009 & 2010 & $2007-2010$ \\
\hline Eigenvalues & I & 0.122 & 0.088 & 0.088 & 0.175 & 0.065 \\
$F$-ratio & & 35.706 & 22.551 & 22.363 & 73.703 & 69.328 \\
$p$ value & & 0.0020 & 0.0020 & 0.0020 & 0.0020 & 0.0020 \\
Trace & I-IV & 0.154 & 0.144 & 0.112 & 0.190 & 0.088 \\
$F$-ratio & & 6.015 & 5.131 & 3.735 & 0.551 & 12.133 \\
$p$ value & & 0.0020 & 0.0020 & 0.0020 & 0.0020 & 0.0020 \\
\hline
\end{tabular}

According to the ordination diagram (Fig. 1), the occurrence of spores of Alternaria, Drechslera type and Cladosporium was associated with the highest TME and DP values, Ganoderma, Epicoccum and Didymella - with moderate values, whereas Leptosphaeria and Torula — with the lowest values. Following the gradient of increasing relative humidity of air, the occurrence of spores of Didymella and Leptosphaeria was related to the highest RH values, whereas Torula and Alternaria - to the lowest values. The spores of Ganoderma, Epicoccum, Drechslera type and Cladosporium occurred at moderate values of relative humidity of air. The maximum abundance of Leptosphaeria and Didymella spores was observed at the highest values of the last statistically significant variable-WINDME, at the moderate values-Ganoderma, Epicoccum and Torula, and at the lowest values-Cladosporium, Drechslera type and Alternaria.

Additionally CCA was performed for each of the 4 years separately in order to determine the dynamics of the relationship between the composition of fungal spores in the air and meteorological variables. In 2007 and 2008, similar values of the total variance in the spore data, explained by the meteorological factors, were found (24.1-24.4\%), slightly lower in 2009 $(20.3 \%)$, while the highest-in 2010 (32.6\%) (Table 1).

In 2007, there were four statistically significant variables: DP, RH, TME and WINDME, which explained a total of $20.4 \%$ of the variance of the spore composition. The largest contribution to the total variation of fungal spore composition in that year had DP (14.1\%) (Table 3). In that year, the annual mean of dew point temperature was the highest in comparison with other years (Table 4).

In 2008, a statistically significant variables were DP and $\mathrm{RH}$, which explained $18.7 \%$ of the total variance.
The largest range of total variation in the spore composition was explained by the DP (12.5\%), as in the previous year. Range of total variation, which was explained by RH (6.2\%), was the highest in comparison to the variability of the spore composition, which was explained by this variable in other years (Table 3 ). In that year, the annual mean of relative humidity was the lowest in comparison to other years (Table 4).

In 2009, statistically significant were two meteorological variables: DP and TME, which explained a total of $15.2 \%$ of the variance. The largest range of the total variance in the spore data was explained by the TME (13.5\%), as in the next year (Table 3).

In 2010, as many as five variables were statistically significant: DP, RH, TME, WINDME and PRECIP, that explained a total of $32.3 \%$ of the variance of the spore composition. The largest contribution to the total variation of fungal spore composition in that year was TME (23.8\%) (Table 3). In that year, the annual mean of air temperature was the lowest in comparison with other years. The annual mean of dew point temperature also reached the lowest value, compared with other years, and the annual sum of precipitation and annual mean of wind speed reached the highest values (Table 4).

Only one meteorological variable (DP) had a statistically significant impact on the total variance of the occurrence of airborne fungal spores in all 4 years (explaining from 1.7 to $14.1 \%$ of the total variance). The other statistically significant variables impacted spore composition differently in different years: RH explained a part of the total variance in the occurrence of spores in 2007, 2008 and 2010 (from 1.5 to $6.2 \%$ ), TME-in 2007, 2009 and 2010 (from 1.6 to $23.8 \%$ ), WINDME-in 2007 and 2010 (from 1.5 to $1.7 \%$ ), PRECIP—only in 2010 (1.7\%) (Table 3).

According to the ordination diagrams, made separately for each year of the study (Fig. 2), and taking 


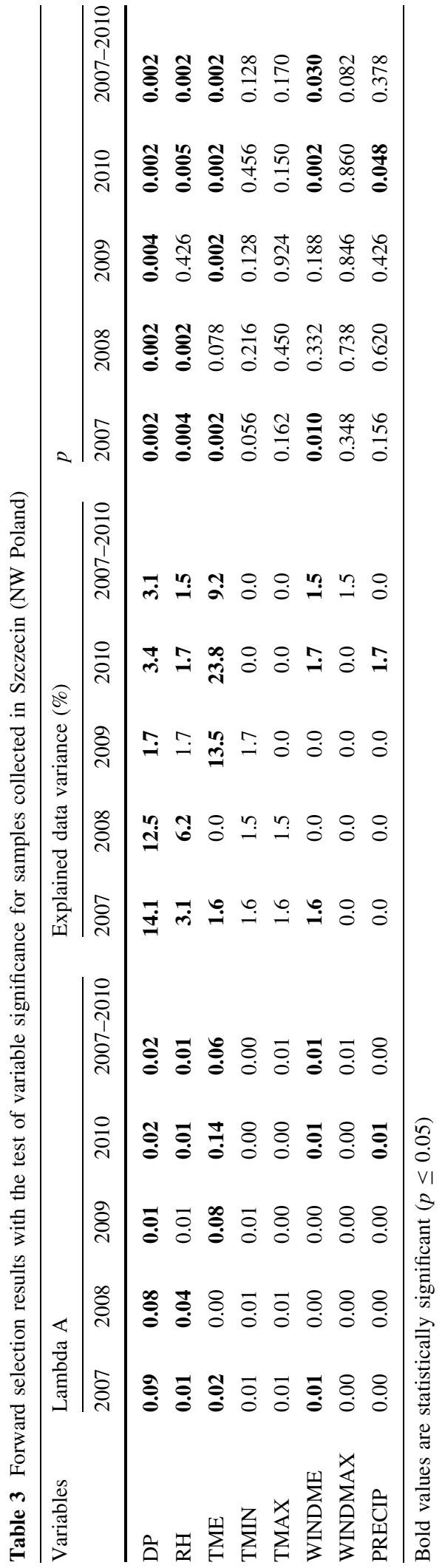

into account only statistically significant meteorological variables, in 2007, almost all examined airborne fungal spores (with the exception of Torula) occurred in the same, moderate range of values of meteorological variables. In 2008, most of spore types occurred also at moderate values of meteorological variables, but with two exceptions (Torula and Alternaria). In 2009, greater differentiation was observed in the occurrence of spore types. In 2010, the presence of most spore types was related to the lowest values of meteorological variables.

\section{Discussion}

The fungal spore concentrations in the air have been extensively studied in modern times. It is a matter of prime concern to the mycologist studying the epidemiology of plant diseases. In medicine, the importance of fungal spores in the air has been emphasized in connection with allergic reactions with a wide spectrum of clinical forms. Because fungal spores are an important component of bioaerosol and also considered to act as an indicator of the level of atmospheric bio-pollution, a better understanding of these phenomena demands a detailed survey of airborne particles. In addition, many types of spores are allergens, and their presence in the air in suitable formulations is very important from the human health point of view (Gravesen 1979).

Meteorological factors are known to influence the production, release and dispersal of aeroallergens, which vary from place to place and from season to season. In this study, results of CCA from the 4-year period showed four meteorological variables (mean air temperature, dew point, relative humidity and mean wind speed), which most influenced the composition of spores in the air.

The largest range of variation in spore composition in the air in north-western Poland (2007-2010) was explained by mean air temperature. As have been obtained in other studies, the occurrence of Cladosporium, Alternaria, Drechslera type, Ganoderma and Epicoccum spores is positively correlated with the air temperature (Hjelmroos 1993; Li and Kendrick 1995a; Herrero et al. 1996; Craig and Levetin 2000; Troutt and Levetin 2001; Peternel et al. 2004; Kasprzyk et al. 2004; Stępalska and Wołek 2005; Grinn-Gofroń 2008; Oliveira et al. 2009b). Such composition of spores present 


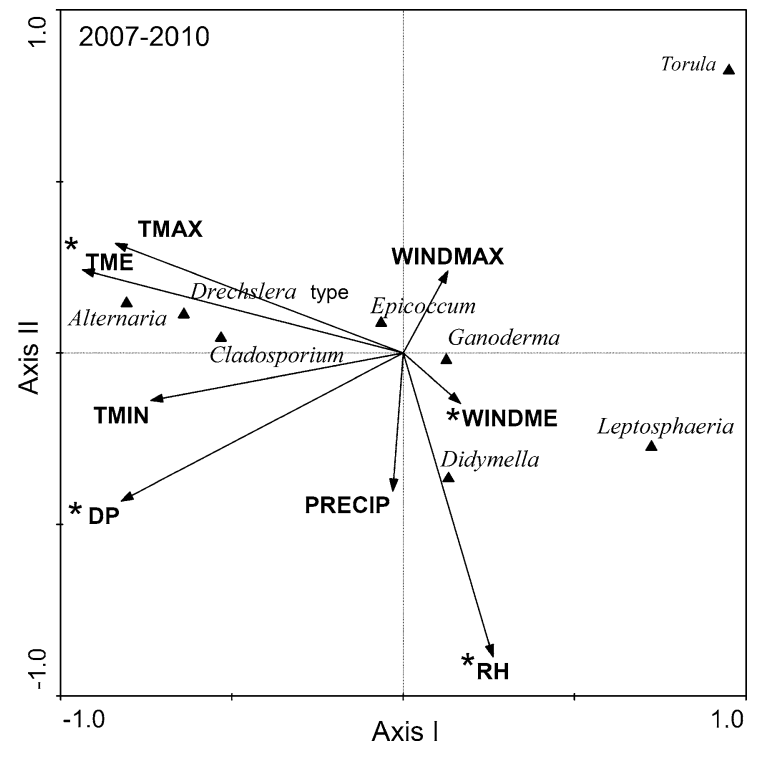

Fig. 1 Diagram of fungal spore and meteorological variable ordination along the first two CCA axes for samples collected in Szczecin (NW Poland); total for all years of the study (2007-2010)

in high concentrations in the air is one of the main causes of allergies in humans (Gravesen 1979; Chapman and Williams 1984; Mitakakis and Guest 2001; Oliveira et al. 2007). It occurs most frequently in summer and early autumn. Airborne fungi (especially allergenic types) are mainly mesophilic (optimal temperature for growth $20-40{ }^{\circ} \mathrm{C}$ ), and some are psychrotolerant (optimum below $20^{\circ} \mathrm{C}$ ) (Gravesen 1979).

Among the above-mentioned spore types, in our 4-year study, the maximum abundance of Alternaria, Drechslera type and Cladosporium spores was observed at higher mean temperature values than those of Ganoderma and Epicoccum spores.

Among other types of spores in our study, the occurrence of Didymella spores was associated with the moderate mean temperature values, nevertheless the relationship was weaker than in case of previous spore types. Wahl and Kersten (1991) found that the release and dispersal of Didymella spores was not greatly affected by air temperature.

Leptosphaeria and Torula spores were related to the lowest mean temperature values in north-western Poland; nonetheless, in case of Torula spores, the relationship was very weak. Leptosphaeria was reported as potentially allergenic in Great Britain, due to the fact that a few percent of vulnerable patients reported positive responses in skin tests (Lacey 1996).
Hasnain (1993) reported that number of Leptosphaeria spores had a statistically significant correlation with the air temperature in the night.

According to the reports of Chapman and Williams (1984), Torula can be a potential allergen, which in some sensitive people evokes hay fever and asthma symptoms. Torula spores occur frequently, however, in low numbers and represent only a few percent of the aeromycoflora tested (Ibáńez Henriquez et al. 2001; La-Serna et al. 2002; Oliveira et al. 2007; Sen and Asan 2001; Vittal and Krishnamoorthi 1981). Probably due to the occurrence in the air in low concentrations, Torula does not have a strong dependence with meteorological parameters.

The second most important meteorological parameter which affected the composition of spores in the air in our study was dew point temperature. This factor is strongly associated with the previously discussed meteorological variable, and that results in similar relationships. The maximum abundance of Alternaria spores was observed at the highest values of dew point temperature; however, it was not strong as mean air temperature. Sensitivity analysis of the artificial neural network showed dew point temperatures as the variable positively influencing the presence of Alternaria (Grinn-Gofroń and Strzelczak 2008a). The contrary results for dew point temperature were obtained by Troutt and Levetin (2001). Differences in the results from the discussed studies are probably caused by various methodologies applied. In this investigation, the long-term time series of daily concentrations were analyzed while Grinn-Gofroń and Strzelczak (2008a) created artificial neural network model for daily concentrations in spore seasons. In turn, multiple regression models by Troutt and Levetin (2001) concerned daily concentrations only in May 1999 and that month represented climatic extremes (unusually high precipitation). Moreover, artificial neural networks, opposite to multiple regression, can model nonlinear relationships. Grinn-Gofron and Strzelczak (2008a) revealed that the dependence of Alternaria spore concentration on dew point temperature and humidity was unimodal with a decline in spore content at high values of the discussed meteorological parameters. High precipitation in May 1999 studied by Troutt and Levetin (2001) caused high humidity and dew point temperature. Thus, the situation might have corresponded with meteorological conditions after the inflection point of Alternaria-dew point/ humidity curves. 
Table 4 Annual, mean values of meteorological parameters for Szczecin in 2007-2010

\begin{tabular}{lrrrr}
\hline Meteorological parameters & 2007 & 2008 & 2009 & 2010 \\
\hline Annual mean of air temperature $\left({ }^{\circ} \mathrm{C}\right)$ & 9.6 & 9.8 & 9.5 & 9.0 \\
Annual mean of dew point temperature $\left({ }^{\circ} \mathrm{C}\right)$ & 6.4 & 5.2 & 5.4 & 5.0 \\
Annual sum of precipitation $(\mathrm{mm})$ & 788.2 & 669.9 & 79.4 & 81.7 \\
Annual mean of relative humidity $(\%)$ & 81.8 & 2.9 & 3.1 & 5.1 .5 \\
Annual mean of wind speed $(\mathrm{m} / \mathrm{s})$ & 3.4 & & 5.7 \\
\hline
\end{tabular}
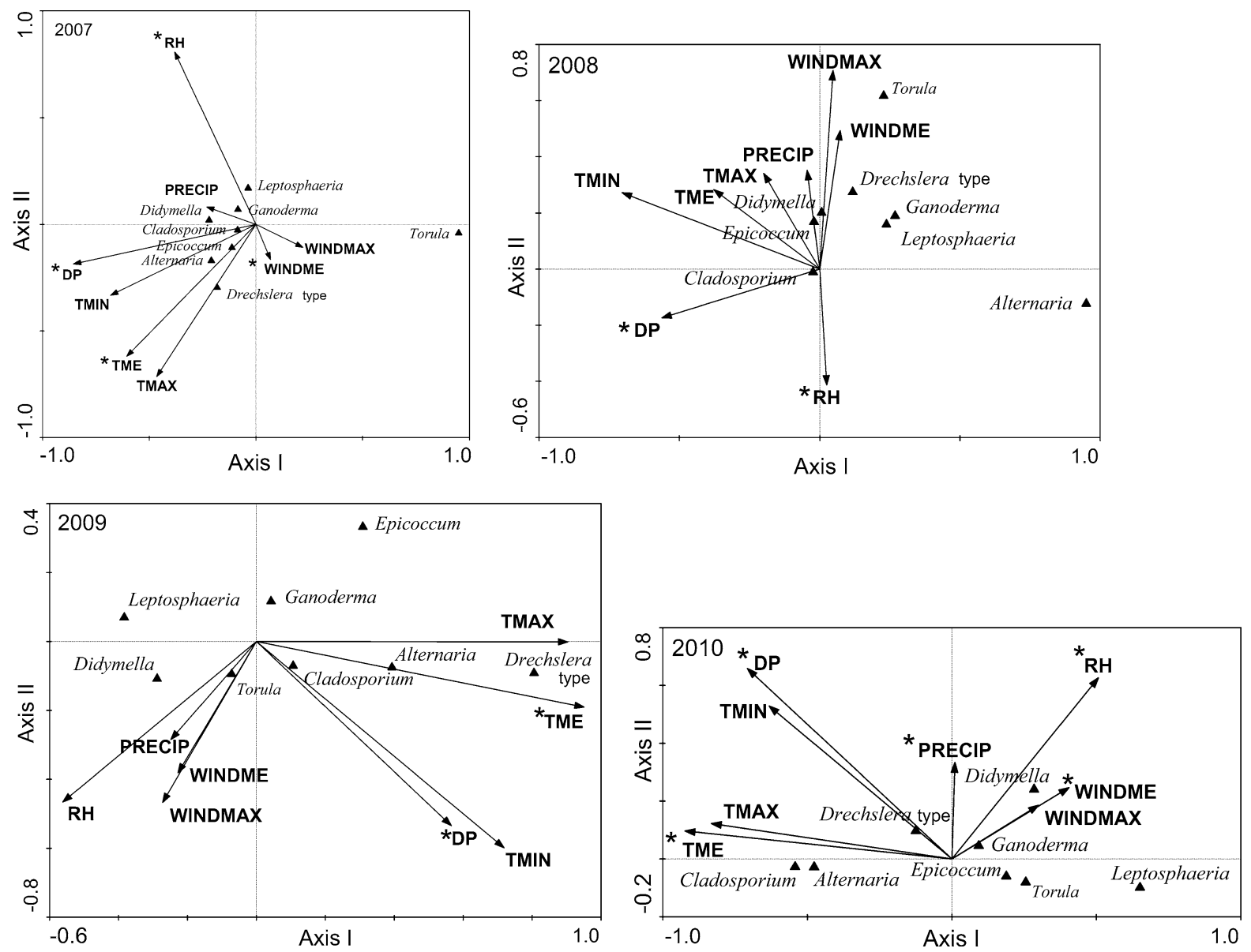

Fig. 2 Diagrams of fungal spore and meteorological variable ordination along the first two CCA axes for samples collected in Szczecin (NW Poland); separately for each year of the study $(2007,2008,2009,2010)$

The third most important meteorological variable in our 4-year study was relative humidity. It is certain that relative humidity has an important influence on the aeromycoflora, mainly on spores belonging to Ascomycetes and Basidiomycetes. Inglod (1971) wrote that ascus dehiscence mechanisms are basically hydrostatic in nature. In many Ascomycetes, high osmotic pressure, which is elevated by transformation of osmotically inactive carbohydrates into osmotically active sugars, develops within the ascus either by the direct absorption of water from the air or by the swelling of muscilage within the ascus (Moore-Landecker 1990). The resulting pressure leads to an explosive release of the ascospores into the turbulent atmosphere. Ascospores are often abundant in the air during and after rainfall, when the level of humidity is sufficiently high (Allitt 1986). 
Active discharge of basidiospores in most species of Basidiomycota is powered by the rapid movement of a droplet of fluid, called Buller's drop, over the spore surface. Upon maturity of a basidiospore, carbohydrates present in the cell wall begin to serve as condensation loci for water vapor in the air. At the pointed tip of the spore closest to the supporting basidium, Buller's drop accumulates as a large, spherical water droplet. At the same time, condensation occurs in thin film on the adaxial face of the spore. When these two bodies of water coalesce, the release of surface tension and the sudden change in the center of mass leads to sudden discharge of the basidiospore (Van Neil et al. 1972; Webster et al. 1984; Noblin et al. 2009).

Spores, which the highest levels recorded during the dry and hot weather (Alternaria, Torula, Cladosporium, Drechslera type, Epicoccum) in case of humidity, have shown an inverse dependence. The concentrations of these "dry-weather spore types" decreased. Sen and Asan (2001), Stępalska and Wołek (2005), Grinn-Gofroń (2008), Oliveira et al. (2009b) found a negative correlation between concentration of Cladosporium, Alternaria, Drechslera type, Epicoccum spores and relative humidity. In our study, the maximum occurrence of Alternaria spores was also associated with the lowest relative humidity, while the maximum occurrence of spores of Didymella and Leptosphaeria was related to the high humidity. Similar results have been obtained in other studies (Harries et al. 1985; Richardson 1996). Richardson (1996) concluded that the high humidity resulting from low temperature and dew formation in the early hours was the reason for high concentrations of Didymella spores in the atmosphere.

The active (violent or forcible) and passive discharge of basidiospores occur in almost equal proportions in the Basidiomycota. Discharge of basidiospores requires atmospheric moisture, although the mechanism is not completely understood. Basidiomycetes exhibiting a forcible mechanism of discharge probably use an interaction between a gasbubble mechanism and an electrostatic mechanism (Saville 1965). If a typical gilled Hymenomycetes can absorb adequate moisture from a rain, it likely can maintain a stable microclimate inside the basidiocarp to enhance spore release and dispersal regardless of the humidity surrounding the basidiocarp. Spore release would continue until the moisture available in the basidiocarp, and outlying mycelium was used up (Dube 2005). In our study, the maximum abundance of Ganoderma spores was observed at the moderate values of relative humidity, although - as was stated by Haard and Kramer (1970)—basidiospores are frequently seen when the air humidity is high. Ganoderma spores are considered to be a moist-air spore type because their concentrations showed marked seasonal and diurnal differences with the highest numbers during the wet season, and water is an important factor involved in its spore release. This agrees with the reports of McCracken (1987) and Hasnain et al. (2004), who stated that humidity levels of about $70 \%$ were associated with increased concentrations of Ganoderma spores. The diurnal pattern with a peak early in the morning and the secondary peak late in the evening was noted in England (London and Worcester) (Lacey 1962; Sadyś et al. 2014), Canada (Tarlo et al. 1979) and New Zealand (Hasnain et al. 1984).

The last statistically significant variable in our 4-year study was wind speed. This factor plays an important role in spore release and dispersal. McCartney (1991) noted that information on the strength of spore attachment and the values of threshold wind speed are not known for the vast majority of fungi. The long-distance dispersal of spores depends on wind conditions, but the detachment of spores dispersed in dry conditions is also strongly influenced by wind (Mallaiah and Rao 1982). The studies of Lin and Li (2000) showed a strong negative correlation between fungal spore concentration and wind speed when the wind speed was under $5 \mathrm{~m} / \mathrm{s}$. However, the fungal concentration increased as the wind speed was higher than $5 \mathrm{~m} / \mathrm{s}$. The authors took this to be evidence of the dilution effect of wind speed being overcome by more particles being raised in higher winds. Jones and Harrison (2004) concluded that maximum wind speed has to exceed a threshold speed to remove material from a surface by either blow or movement of the surface. However, at higher speed, spore concentrations may become diluted. Packe and Ayers (1986) suggest that turbulent winds could increase the release of fungal spores or draw up sedimented fungal spores and resuspend them in the air.

In our analysis Alternaria, Cladosporium and Drechslera type spores showed dependence on the lowest value of mean wind speed, whereas Leptosphaeria and Didymella-on the highest. A negative 
correlation between the Alternaria spores count and the wind speed was observed by Levetin and Dorsey (2006) and by Hasnain (1993). Lopez and Salvaggio (1983) also confirmed that high wind speed produced a decreased atmospheric concentration of Alternaria spores count. The lack of correlation between the concentration of Cladosporium spores and wind speed was recorded by Levetin and Dorsey (2006), Hasnain (1993), Lopez and Salvaggio (1983), and the same results for Drechslera type spore concentration were recorded by Troutt and Levetin (2001).

The effects of meteorological factors varied among years. In our analysis, similarly to $\mathrm{Li}$ and Kendrick (1995b), the mean values of meteorological parameters were generally more important than their maximum and minimum. Differences in the dependences between meteorological parameters and fungal spore levels can be observed in every year, and this is most likely due to the different average values of meteorological parameters in every year studied. However, the spore behavior is a dynamic and complex phenomenon, and meteorological factors alone do not reflect the global status of the atmosphere. Therefore, it is difficult to separate the individual effects of different meteorological parameters, since fungi react simultaneously to a combination of factors (Azcón-Bieito and Talón 2000). All methods used in the aerobiological analysis should be selected to describe the effects of all meteorological factors on the concentration and composition of spores in the air. Such results, related to the ecology of fungi, would give more reliable view of fungal spore occurrence in the air.

Open Access This article is distributed under the terms of the Creative Commons Attribution License which permits any use, distribution, and reproduction in any medium, provided the original author(s) and the source are credited.

\section{References}

Allitt, U. (1986). Identity of airborne hyaline, one-septate ascospores and their relation to inhalant allergy. Transactions of the British Mycological Society., 87, 147-154.

Angulo-Romero, J., Mediavilla-Molina, A., \& DominquezVilches, E. (1999). Conidia of Alternaria in the atmosphere of the city of Cordoba, Spain in relation to meteorological parameters. International Journal of Biometeorology, 43, 45-49.
Azcón-Bieito, J., \& Talón, M. (2000). Fundamentos de fisiologia vegetal. Madrid: McGraw-Hill.

British Aerobiology Federation. (1995). Airborne pollens and spores. A guide to trapping and counting (1st ed.). Rotherham, UK: Natl Pollen \& Hayfever Bureau.

Chapman, J., \& Williams, S. (1984). Aeroallergens of the southeast Missouri area: a report of skin test frequencies and air sampling data. Annals of Allergy, Asthma \& Immunology, 52, 411-418.

Craig, R. L., \& Levetin, E. (2000). Multi-year study of Ganoderma aerobiology. Aerobiologia, 16, 75-80.

Dube, H. C. (2005). An introduction to fungi (3rd ed., p. 568). Delhi: Vikas Publishing House PUT Ltd.

Gravesen, S. (1979). Fungi as a cause of allergic disease. Allergy, 34, 135-154.

Grinn-Gofron, A. (2008). The variation in spore concentrations of selected fungal taxa associated with weather conditions in Szczecin, Poland, 2004-2006. Grana, 47, 139-146.

Grinn-Gofron, A., \& Strzelczak, A. (2008a). Artificial neural network models of relationships between Alternaria spores and meteorological factors in Szczecin (Poland). International Journal of Biometeorology, 52, 859-868.

Grinn-Gofron, A., \& Strzelczak, A. (2008b). Artificial neural network models of relationships between Cladosporium spores and meteorological factors in Szczecin (Poland). Grana, 47, 304-314.

Grinn-Gofroń, A., \& Strzelczak, A. (2009). Hourly predictive ANN and MRT models of Alternaria and Cladosporium spore concentrations in Szczecin (Poland). International Journal of Biometeorology, 53, 555-562.

Grinn-Gofron, A., \& Strzelczak, A. (2011). The effects of meteorological factors on the occurrence of Ganoderma sp. spores in the air. International Journal of Biometeorology, $55,235-241$.

Haard, R. T., \& Kramer, C. L. (1970). Periodicity of spore discharge in the hymenomycetes. Mycologia, 62, 1145.

Harries, M. G., Lacey, J., Tee, R. D., Cayley, G. R., \& Newman Taylor, A. J. (1985). Didymella exitialis and late summer asthma. Lancet, 1, 1063-1066.

Hasnain, S. M. (1993). Influence of meteorological factors on the air spora. Grana, 32, 184-188.

Hasnain, S. M., Al-Frayth, A., Khatija, F., \& Al-Sedairy, S. (2004). Airborne Ganoderma basidiospores in a country with desert environment. Grana, 43, 111-115.

Hasnain, S. M., Newhook, F. J., Wilson, J. D., \& Corbin, J. B. (1984). First report of Ganoderma allergenicity in New Zealand. New Zealand Journal of Science, 27, 261-267.

Herrero, B., Fombella-Blanco, M. A., Fernández-Gonzáles, D., \& Valencia-Barrera, R. M. (1996). The role of meteorological factors in determining the annual variation of Alternaria and Cladosporium spores in the atmosphere of Palencia, 1990-1992. International Journal of Biometeorology, 39, 139-142.

Hjelmroos, M. (1993). Relationship between airborne fungal spore presence and weather variables. Grana, 32, 40-47.

Ibáńez Henriquez, V., Rojas Villegas, G., \& Roure Nolla, J. M. (2001). Airborne fungi monitoring in Santiago, Chile. Aerobiologia, 17, 137-142.

Inglod, C. T. (1971). Fungal spores: Their liberation and dispersal. Oxford: Clarendon Press. 
Jones, A. M., \& Harrison, R. M. (2004). The effects of meteorological factors on atmospheric bioaerosol concentrationsa review. Science of the Total Environment, 326, 151-180.

Kasprzyk, I., Rzepowska, B., \& Wasylów, M. (2004). Fungal spores in the atmosphere of Rzeszów (South-East Poland). Annals of Agriculture and Environmental Medicine., 11, 285-289.

Katial, R. K., Zhang, Y. M., Jones, R. H., \& Dyer, P. D. (1997). Atmospheric mold spore counts in relation to meteorological parameters. International Journal of Biometeorology, 41, 17-22.

Lacey, M. E. (1962). The summer air-spora of two contrasting adjacent rural sites. Journal of Geneneral Microbiology., 29, 485-501.

Lacey, J. (1996). Spore dispersal-its role in ecology and disease: the British contribution to fungal aerobiology. Mycological Research, 100, 641-660.

Lacey, J., \& Allitt, U. (1995). Airborne pollen and spores guide to trapping and counting (pp. 1-60). Harpenden: The British Aerobiology Federation.

La-Serna, I., Dopazo, A., \& Aira, M. J. (2002). Airborne fungal spores in the Campus of Anchieta (La laguna, Tenerife/ Canary Is). Grana, 41, 119-123.

Levetin, E., \& Dorsey, K. (2006). Contribution of leaf surface fungi to the air spora. Aerobiologia, 22, 3-12.

Li, D. W., \& Kendrick, B. (1995a). A year-round outdoor aeromycological study in Waterloo, Ontario, Canada. Grana, 34, 199-207.

Li, D. W., \& Kendrick, B. (1995b). A year-round study on functional relationships of airborne fungi with meteorological factors. International Journal of Biometeorology, 39, 74-80.

Lin, W. H., \& Li, C. S. (2000). Associations of fungal aerosols, air pollutants and meteorological factors. Aerosol Science and Technology, 32, 359-368.

Lopez, M., \& Salvaggio, E. J. (1983). Climate-Weather-Air Pollution. In E. Middleton, C. E. Reed, \& E. F. Ellis (Eds.), Allergy: Principle and practice (2nd ed., pp. 1203-1214). St. Louis: Mosby.

Mallaiah, K., \& Rao, A. S. (1982). Aerial dissemination of uredinospores of groundnut rust. Transactions of the British Mycological Society, 78, 21-28.

McCartney, H. A. (1991). Airborne dissemination of plant pathogens. Journal of Applied Bacteriology, 70, 49-59.

McCracken, F. L. (1987). Factors affecting the spore release of Ganoderma applanatus. Journal of the Academy of Marketing Science, 32, 55-60.

Mitakakis, T. Z., Clift, A., \& McGee, P. A. (2001). The effect of local cropping activities and weather on the airborne concentration of allergenic of Alternaria spores in rural Australia. Grana, 40, 230-239.

Mitakakis, T. Z., \& Guest, D. I. (2001). A fungal spore calendar for the atmosphere of Melbourne, Australia for the year 1993. Aerobiologia, 17, 171-176.

Moore-Landecker, E. (1990). Fundamentals of the fungi (3rd ed.). Englewood Cliffs, NJ: Prentice-Hall.

Noblin, X., Yang, S., \& Dumais, J. (2009). Surface tension propulsion of fungal spores. Journal of Experimental Biology, 212, 2835-2843.

Oliveira, M., Abreu, I., Ribeiro, H., \& Delgado, J. L. (2007). Fungal spores in the atmosphere in the city of Porto and its allergological implications. Revista Portugesa de Immunoalergologia., 15(1), 61-85.

Oliveira, M., Ribeiro, H., \& Abreu, I. (2009a). Annual variation of fungal spores in atmosphere of Porto: 2003. Annals of Agriculture and Environmental Medicine, 12, 309-315.

Oliveira, M., Ribeiro, H., \& Delgado, J. L. (2009b). The effects of meteorological factors on airborne fungal spore concentration in two areas differing in urbanization level. International Journal of Biometeorology, 53, 61-73.

Packe, G. E., \& Ayers, J. G. (1986). Aeroallergen skin sensitivity in patients with severe asthma during a thunderstorm. Lancet, 1, 850-851.

Peternel, R., Čulig, J., \& Hrga, I. (2004). Atmospheric concentrations of Cladosporium spp. and Alternaria spp. spores in Zagreb (Croatia) and effects of some meteorological factors. Annals of Agriculture and Environmental Medicine, 11, 303-307.

Richardson, M. J. (1996). The occurrence of airborne Didymella spores in Edinburgh. Mycological Research, 100(2), 213-216.

Sadyś, M., Skjøth, C. A., \& Kennedy, R. (2014). Back-trajectories show export of airborne fungal spores (Ganoderma sp.) from forests to agricultural and urban areas in England. Atmospheric Environment, 84, 88-99.

Saville, D. B. O. (1965). Spore discharge in Basidiomycetes: a unified theory. Science, 147, 165-166.

Sen, B., \& Asan, A. (2001). Airborne fungi in vegetable growing areas of Edirne, Turkey. Aerobiologia, 17, 69-75.

Software for Canonical Community Ordinantion (version 4.5). (2002). Microcomputer Power, Ithaca, NY, USA.

Stennett, P. J., \& Beggs, P. J. (2004). Alternaria spores in the atmosphere of Sydney, Australia, and relationships with meteorological factors. International Journal of Biometeorology, 49, 98-105.

Stępalska, D., \& Wołek, J. (2005). Variation in fungal spore concentrations of selected taxa associated to weather conditions in Cracow, Poland, in 1997. Aerobiologia, 21, 43-52.

Tarlo, S. M., Bell, B., Srinivasan, J., Dolovich, J., \& Hargreave, F. E. (1979). Human sensitization to Ganoderma antigen. Journal of Allergy and Clinical Immunology, 64, 43-49.

ter Braak and Šmilauer (2002) CANOCO Reference Manual and Use $=r$ 's Guide to Canoco for Windows:

Troutt, C., \& Levetin, E. (2001). Correlation of spring spore concentrations and meteorological conditions in Tulsa, Oklahoma. International Journal of Biometeorology, 45, 64-74.

Van Neil, C. B., Garner, G. E., \& Cohen, A. L. (1972). On the mechanism of ballistospore discharge. Archiv für Mikrobiologie, 84, 129-140.

Vittal, B. P. R., \& Krishnamoorthi, K. (1981). Air spora of an agricultural farm in Madras, India. Grana, 20, 61-64.

Wahl, P. G., \& Kersten, W. (1991). Fusarium and Didymella neglected spores of the air. Aerobiologia, 7, 111-117.

Webster, J., Davey, R. A., Duller, G. A., \& Ingold, C. T. (1984). Ballistospore discharge in Itersonilia perplexans. Transactions of the British Mycological Society, 82, 13-29.

Woś, A. (1999). The climate of Poland. PWN, Warszawa, Poland: Wyd. Nauk. 